\title{
POLYMER-SURFACTANT MONO AND BILAYERS
}

\section{LANGEVIN}

Centre de Recherche Paul Pascal ${ }^{1}$

\section{MONOCOUCHES ET BICOUCHES DE POLYMERES ET DE TENSIOACTIFS}

Malgré de nombreux travaux sur les associations entre polymères et tensioactifs en solution, les associations localisées sur des surfaces ont été beaucoup moins étudiées. Dans cette présentation différents exemples seront présentés: des polymères non solubles dans l'eau étalés à la surface de solutions aqueuses de tensioactifs, des polymères hydrosolubles adsorbés avec des molécules de tensioactifs à la surface de la solution.

La première situation sera illustrée par du PDMS (polydiméthylsiloxane) étalé sur des monocouches de tensioactifs de différentes longueurs de chaînes. La pénétration des chaînes de polymères dans la couche de tensioactifs a été étudiée à l'aide de différentes techniques (tension superficielle, ellipsométrie, réflectivité de neutrons)

Des exemples de la deuxième situation seront donnés à l'aide de deux polyélectrolytes (polystyrène sulfonate PSS and polyacrylamide sulfonate PAMPS) et différents tensioactifs (ioniques et non-ioniques). Les mesures de tension superficielles de solutions diluées de tensioactif non ionique $\left(C_{10} E_{5}\right)$ montrent qu'il existe une forte interaction avec le PSS et pas d'interaction avec le PAMPS. Cet effet est probablement dâ au caractère hydrophobe plus important du squelette de la chaîne de PSS. Des expériences de diffraction des rayons $X$ et ce microscopie électronique sur des phases lamellaires en présence de PSS montrent que les chaînes de polymères sont imbriquées à l'intérieur de la bicouche de tensioactifs. Les interactions entre PSS et PAMPS avec des tensioactifs cationiques (DTAB) de charges opposées ont aussi été étudiées par tension superficielle, ellipsométrie et appareil de force de film mince. Un complexe de surface étendu polymère/tensioactif se forme et un phénomène de stratification est observé dans les films minces formés à partir des solutions.

\section{POLYMER-SURFACTANT MONO AND BILAYERS}

Although there are many studies of association of polymers and surfactants in solution, much less is known about their association at surfaces. In this paper, several examples will be presented: water insoluble polymers spread at the surface of surfactant aqueous solutions, water soluble polymers adsorbed with the surfactant at the surface of the solution.

Examples of the first case will be given with PDMS (polydimethylsiloxane) spread onto monolayers of surfactants of different chain lengths. The penetration of the polymer into the surfactant layer has been studied with different techniques (surface tension, ellipsometry, neutron reflectivity).

Examples of the second case will be given with two different polyelectrolytes (polystyrene sulfonate PSS and polyacrylamide sulfonate PAMPS) and various surfactants (ionic and nonionic). 
Surface tension measurements of the dilute solutions with a nonionic surfactant $\left(\mathrm{C}_{10} \mathrm{E}_{5}\right)$ show that there is a strong interaction with PSS and no interaction with PAMPS. This is probably due to the larger hydrophobicity of the polymer backbone. X-Ray scattering and electron microscopy experiments on lamellar phases with PSS show that the polymer chains are embedded into the surfactant bilayers. The interaction of PSS and PAMPS with a cationic surfactant (DTAB, opposite charge) has also been studied by surface tension and ellipsometry. An extended polymer-surfactant surface complex is formed at the surface of the solutions.

\section{MONOCAPAS Y BICAPAS DE POLÍMEROS Y DE TEN- SIOACTIVOS}

A pesar de los numerosos trabajos relativos a las combinaciones entre polímeros y tensioactivos en solución, las asociaciones localizadas en las superficies han sido objeto de mucha menor atención en cuanto a su estudio. En esta presentación se exponen distintos ejemplos: polímeros no solubles en el agua, extendidos en la superfice con soluciones acuosas de tensioactivos, polímeros hidrosolubles adsorbidos con moléculas de tensioactivos en la superficie de la solución.

La primera situación habrá de ser ilustrada por el sistema PDMS (polidimetilsiloxano) extendido sobre monocapas de tensioactivo de distintas longitudes de cadenas. La penetración de las cadenas de polímero en la capa de tensioactivos se ha estudiado por medio de distintas técnicas (tensión superficial, elipsometría, reflectividad de neutrones).

Figuran diversos ejemplos de la segunda situación, por medio de dos polielectrolítos (poliestireno sulfonato PSS y poliacrilamida sulfonato PAMPS) así como distintos tensioactivos (iónicos y no iónicos). Las medidas de tensión superficial de soluciones diluidas de tensioactivo no iónico $\left(\mathrm{C}_{10} \mathrm{E}_{5}\right)$ vienen a demostrar la existencia de una elevada interacción con el PSS y ninguna interacción con el PAMPS. Probablemente, este efecto se debe al carácter hidrófobo más improtante del esqueleto de la cadena de PSS. Las experiencias de difracción de los rayos $X$ y de microspcopia electrónica en fases laminares en pressencia de PSS muestran que las cadenas de polímeros se encuentran imbricadas en el interior de la bicapa de tensioactivos. Las interacciones entre PSS y PAMPS con tensioactivos catiónicos DTAB de cargas opuestas se han estudiado también por tensión superficial, elipsometría y aparato de fuerza de película de bajo espesor. Se forma entonces un complejo de superficie amplio polímero/tensioactivo y se observa la aparición de un fenómeno de estratificación en las películas de bajo espesor que se han formado a partir de soluciones.

\section{INTRODUCTION}

Interactions between surfactants and polymers is a rapidly growing field of interest in colloid science [1]. Indeed, many practical systems for industrial applications contain mixtures of polymers and surfactants. These mixtures are widely used as thickeners in water based formulations such as paints, drilling muds, etc. In biology, membranes are beautiful examples of architectures where lipids and proteins form structured complexes. Whereas there is an extensive literature on surfactant solutions on one hand, and polymer solutions on the other hand, much less is known for the mixed solutions. It was argued recently, that polymersurfactant solutions are similar to polymer-polymer solutions [2]. In the case of polyelectrolytes, the influence of the counterions is dominant: because of counterion condensation, the concentration of counterions is enhanced close to the polyion, and this non-uniform distribution represents a loss of entropy compared to the case of a uniform counterion distribution. If two polyelectrolytes of opposite charge are mixed, the two polyions associate, thus releasing the couterions in the solution, and increasing the entropy of the solution. The case of surfactant-polymer mixtures is however less simple, because the surfactant aggregation number in micellar aggregates can vary. However, it was observed that the behaviour of polyelectrolyte-surfactant solutions was similar to the behaviour of polyelectrolyte-polymer solutions: no association for neutral or same charge surfactants, and strong association for opposite charges [2].

In concentrated surfactant solutions, more complex microstructures can be found: cylinders in hexagonal phases, stacks of bilayers in lamellar phases, bicontinuous structures in cubic or sponge phases, etc. There is a general interest in the basic research on the modification of surfactant self-assembly by the addition of polymer molecules and the behaviour of such molecules in confined environment. For polymers solubilised into a surfactant lamellar phase various structural models have been proposed, according to which the polymer molecules may be either confined in the water regions [3] and [4], cross between those regions through the bilayer [5], remain partly on the surface of bilayer and partly inside [6], or remain confined inside bilayers [7].

Although less studied, polymers and surfactants can associate at a surface, in particular at the mixed solution surface. This surface complexation is also important for practical applications such as colloidal stabilization, wettability, adhesion, etc. Complexation 
in bulk or at a surface are generally related [1]. Waterinsoluble polymers also form interesting complexes at the surface of surfactant solutions. These polymers are often used to break foams or to inhibit foam formation.

In this short review, we will present some examples of polymer association with mono and bilayers as studied with various experimental techniques.

\section{POLYDIMETHYLSILOXANE-SURFACTANT MIXED MONOLAYERS}

We have studied an insoluble polymer, polydimethylsiloxane (PDMS), placed at the surface of different surfactant solutions: Aerosol OT (AOT), a double-chain anionic surfactant, alkyl-trimethylammonium bromides $\left(\mathrm{C}_{n} \mathrm{TAB}\right)$, a series of single chain cationic surfactants and pentaethylene glycol mono $n$-decyl ether $\left(\mathrm{C}_{10} \mathrm{E}_{5}\right)$, a single-chain nonionic surfactant. The surfactant solutions are all slightly above the critical micellar concentration ( $\mathrm{cmc}$ ), ensuring a maximum surfactant concentration at the interface on which the polymer is spread. The PDMS molecular weigth was $\mathrm{M}_{w}=10.000\left(\mathrm{M}_{w}, \mathrm{M}_{n}=1.8\right)$. The polymer was applied to the surfaces either pure, as a several microliter droplet, or in a spreading hexane solution.

PDMS alone at the air-water interface forms a fairly dense, compact film with chains essentially parallel to the surface and little looping into the bulk [8]. One can imagine several possibilities for the mixed film: one of the components may be excluded from the interfacial region, leaving a pure film; surfactant and polymer may mix to form a homogeneous film; polymer and surfactant may segregate into patches to form a heterogeneous film; or polymer and surfactant may segregate vertically, forming nearly separate layers at the interface.

In order to determine the structure of the mixed film, the surface tension was first measured. The change in surface tension due to the presence of the polymer, $\Delta \gamma$ is given in Figure 1 for the different substrates, pure water and surfactant solutions. In all cases, $\Delta \gamma$ reaches a plateau value, and a significant variation occurs around a similar concentration value $c_{1} \sim 0.75 \mathrm{mg} / \mathrm{m}^{2}$. Numerically $c_{1}$ corresponds to saturation with a dense layer of monomers adsorbed on the liquid surface.

Ellipsometry experiments were performed to obtain information on the thickness of these layers. Data for the three systems water, $\mathrm{AOT}$ and $\mathrm{C}_{10} \mathrm{E}_{5}$ solutions are

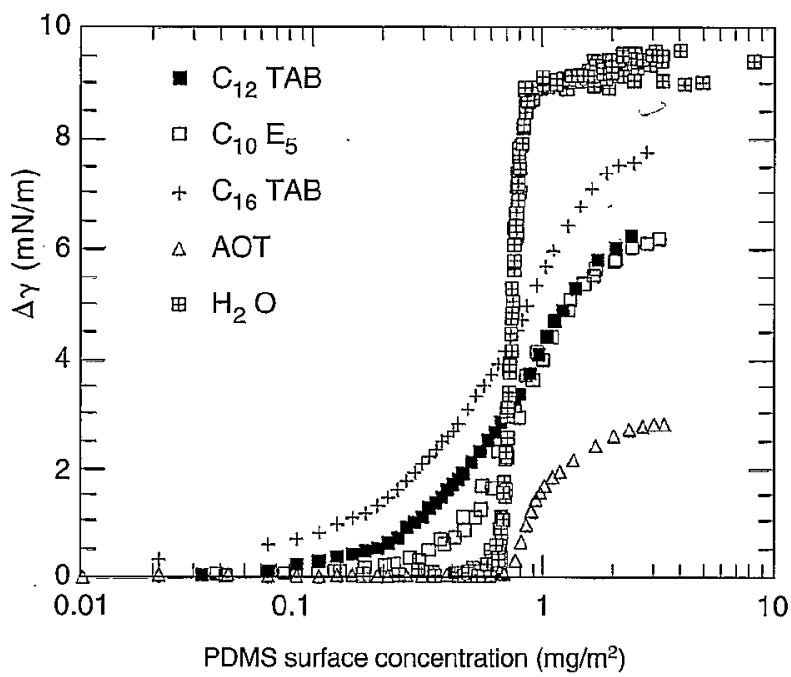

Figure 1

Change in surface tension as a function of polymer concentration on different substrates: pure water (squares with crosses); $\mathrm{C}_{12} \mathrm{TAB}$ (filled squares), $\mathrm{C}_{10} \mathrm{E}_{5}$ (empty squares), $\mathrm{C}_{16} \mathrm{TAB}$ (crosses) and AOT solutions (triangles). After [11].

given in Figure 2. If one assumes that the ellipticity of the substrate, $(\bar{\rho})_{\mathrm{s}}$ is unchanged by the presence of the polymer, and that the polymer form an isotropic layer above the solution with the bulk polymer density and index of refraction, one gets:

$$
(\bar{\rho})=(\bar{\rho})_{\mathrm{s}}+1.02 \cdot 10^{-3} c\left[\mathrm{mg} / \mathrm{m}^{2}\right] .
$$

This prediction is shown as straight lines on Figure 2. The agreement between model and data should not be taken as indicating entirely separate surfactant and polymer layers; it indicates rather that the surfactant surface concentration is little changed by the presence of the polymer, in agreement with the surface tension data, without ruling out mixing between the polymer and the surfactant chains. Note also that the slope for the ellipticity vs. concentration curve is about $15 \%$ less on the $\mathrm{C}_{10} \mathrm{E}_{5}$ than on the AOT substrates: this is at the edge of the $\pm 10 \%$ experimental resolution but, like the surface tension data, suggests a greater effect of the polymer on the former surfactant substrate. This has been demonstrated much more clearly in the neutron reflectivity experiments (see afterwards)

For $c<c_{1}$, the ellipticity on the AOT substrate (but not the $\mathrm{C}_{10} \mathrm{E}_{5}$ substrate) deviates from the simple homogeneous polymer-surfactant bilayer model: as on 


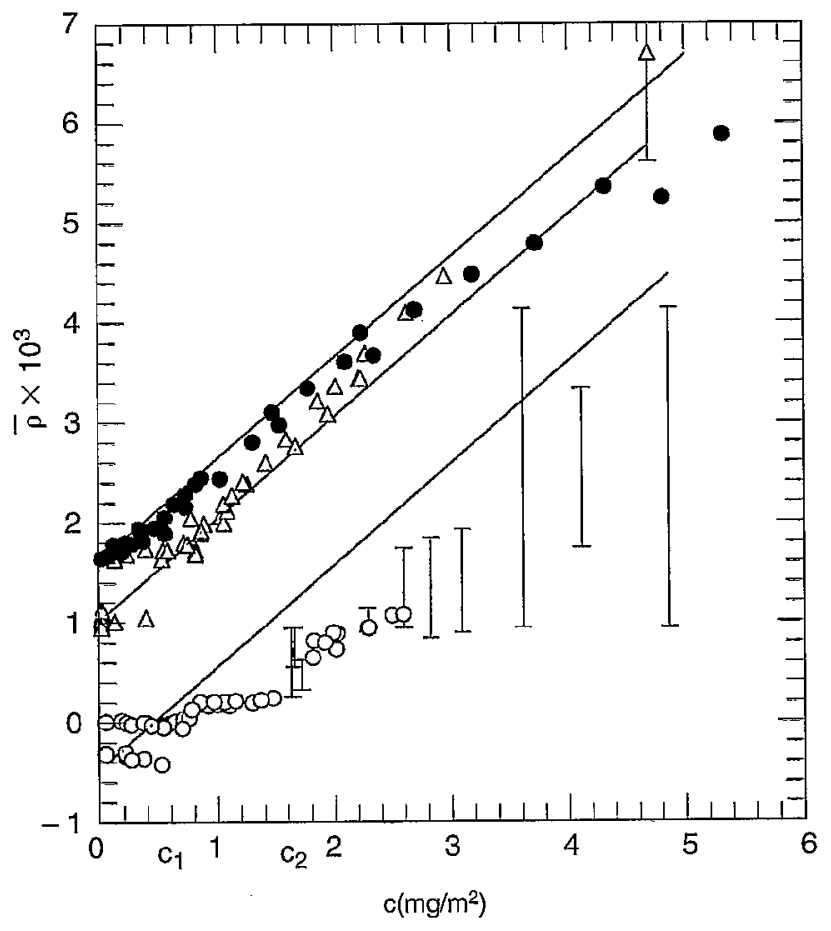

Figure 2

The ellipticity $\bar{p}$ as a function of polymer concentration, for three different substrates:

Pure water $\mathrm{O}$; AOT $\left(\Delta ; c_{b} \sim 2 \mathrm{cmc}\right) ; \mathrm{C}_{10} \mathrm{E}_{5}\left(-c_{b} \sim 2 \mathrm{cmc}\right)$. Bars represent fluctuations in the ellipticity out of the range of error.

Lines: $\bar{\rho}=\bar{\rho}_{s}+1.02 \cdot 10^{-3} \mathrm{cmg} / \mathrm{m}^{2}$. After [8].

water, two ellipticity levels are seen over most of this range, one ellipticity characteristic of the substrate and one at a higher level, without fluctuations between the two. That these reflect a separation into very large (much larger than the $2 \mathrm{~mm}$ beam size) dense and dilute polymer domains has already been demonstrated by Brewster Angle microscopy on pure water substrates, and confirmed here for the AOT substrate as well (9). On the other hand, the polymer film shows no sign of a division into domains on the $\mathrm{C}_{10} \mathrm{E}_{5}$ substrate, neither on the millimeter scale of ellipsometry nor on the micrometer scale of the Brewster angle microscope.

Let us come back to the surface tension data. If the polymer layers lay on the top of the solution, one can identify $\Delta \gamma$ to the polymer surface pressure (this may not be exact if the polymer penetrates somewhat into the surfactant layer). At sufficiently low concentrations that the individual polymer chains do not interact, one expects them to form an ideal gas, or to phase separate into dense and very dilute polymer domains. This last situation is encountered for PDMS on water or AOT solutions below $c_{1}$. For the other surfactants, the change in surface tension is greater than that expected by the ideal gas law in the entire region below $c_{1}$. The polymer chains are therefore already in contact. Theory predicts a semi-dilute regime above the concentration at which the polymer chains mix. The surface pressure is expected to be then independent of molecular weight, following a scaling law $\pi \propto c^{y}$, where $y$ depends on the balance of monomer-monomer and excluded volume forces [10]. For good solvent behavior, one expects $y \sim 3$. The behavior of a polymer in a two-dimensional theta solvent has been more controversial. Recently however, a variety of different theoretical methods have led to $y \sim 8$. For PDMS on water (with a semi-dilute regime starting at $c_{1}$ ), we find $y \geqslant 22$. This high value has been taken as the signal of poor solvent behavior, consistent with phase separation at lower average surface concentrations. Similarly, for AOT, $y=10$. On solutions of $\mathrm{C}_{10} \mathrm{E}_{5}$ on the other hand, we find $y=2$. This dependence is even less than expected for the surface pressure of a two-dimensional polymer in a good solvent. Let us recall however that $\Delta \gamma$ cannot be clearly related to a polymer surface pressure $\pi$, since the polymer may affect the underlying surfactant layer. The exponent $y$ is still smaller for the C ${ }_{n}$ TAB's: $n=9, y=1.7 ; n=10, y=1.55 ; n=12$, $y=1.2 ; n=14$ and $16, y=0.8$ [11].

Neutron and X-ray reflectivity experiments are sensitive to both the thickness and the index of refraction of thin surface layers, allowing for more quantitative data than with ellipsometry, which for monolayers is sensitive only to the product of the thickness and the index of refraction. Neutron reflectivity has the advantage of allowing variation of the contrast between the substrate and the different elements of the film by the method of isotopic substitution: air contrast-matched water, for example, permits a signal due solely to the presence of the film. This recently allowed an exploration of the conformation of the polymer PDMS on pure water and on $\mathrm{AOT}$ and $\mathrm{C}_{10} \mathrm{E}_{5}$ solutions above $c_{1}$ [12]. As expected from surface tension and ellipsometry data analysis, AOT and PDMS form duplex films with negligible interpenetration, whereas $C_{10} E_{5}$ and PDMS layers are mutually interpenetrated (there is about $20 \%$ polymer in the surfactant layer).

It is therefore likely that the exponent y gives a good indication of the state of interpenetration of the two 
layers. We can then conclude that the interpenetration increases with the chain length of the surfactant. The effect of the polar head is less important. This is confirmed by surface tension experiments performed in solutions with added salt. When $\mathrm{KBr}$ is added to $\mathrm{C}_{12} \mathrm{TAB}$ and $\mathrm{AOT}$ solutions, the area per head decreases respectively from $115 \AA^{2}$ to $75 \AA^{2}$ and from $44 \AA^{2}$ to $33 \AA^{2}$ (as obtained from Gibbs equation). Despite of this significant variation of the area occupied by the heads, the surface tension change $\Delta \gamma$ upon addition of polymer does not significantly varies when salt is added.

When larger amounts of polymer are added at the surface, there is a coexistence of (more than monomolecular) films and of macroscopic drops for all solutions except $\mathrm{C}_{16}$ TAB solutions, on which PDMS fully spreads. The first case corresponds to pseudopartial wetting, where long-range interactions across the spread film. limit its thickness, with excess liquid collecting in macroscopic liquid lenses [13]. This wetting behaviour might be relevant to antifoam action.

\section{POLYELECTROLYTES IN LAMELLAR PHASES}

We have studied poly(styrene-co-styrene sulfonate) (PSS), a random copolymer of highly hydrophobic polystyrene and hydrophilic polystyrene sulfonate units, $x$ being the degree of sulfonation or charge content. The polymer used has a molecular weight of $250.000\left(\mathrm{M}_{w} / \mathrm{M}_{n}=2\right)$ [7]. The behaviour of PSS in water is unusual for polyelectrolytes. It has been shown previously using SAXS and SANS results [14] that the structure of PS ${ }_{1-x} \mathrm{NaPSS}_{x}$ in semi-dilute water solutions exhibits stronger correlations than predicted by the correlation hole model [15], thus inferring that the hydrophobicity of the polymer backbone is significant compared to the long-range Coulomb interactions.

Unlike other water soluble polymers, PSS exhibits high affinity towards non-ionic surfactants. We have performed surface tension measurements to probe interactions between the surfactant and polymer molecules in dilute $\mathrm{C}_{12} \mathrm{E}_{5}$ /water solutions. In Figure 3 we show the

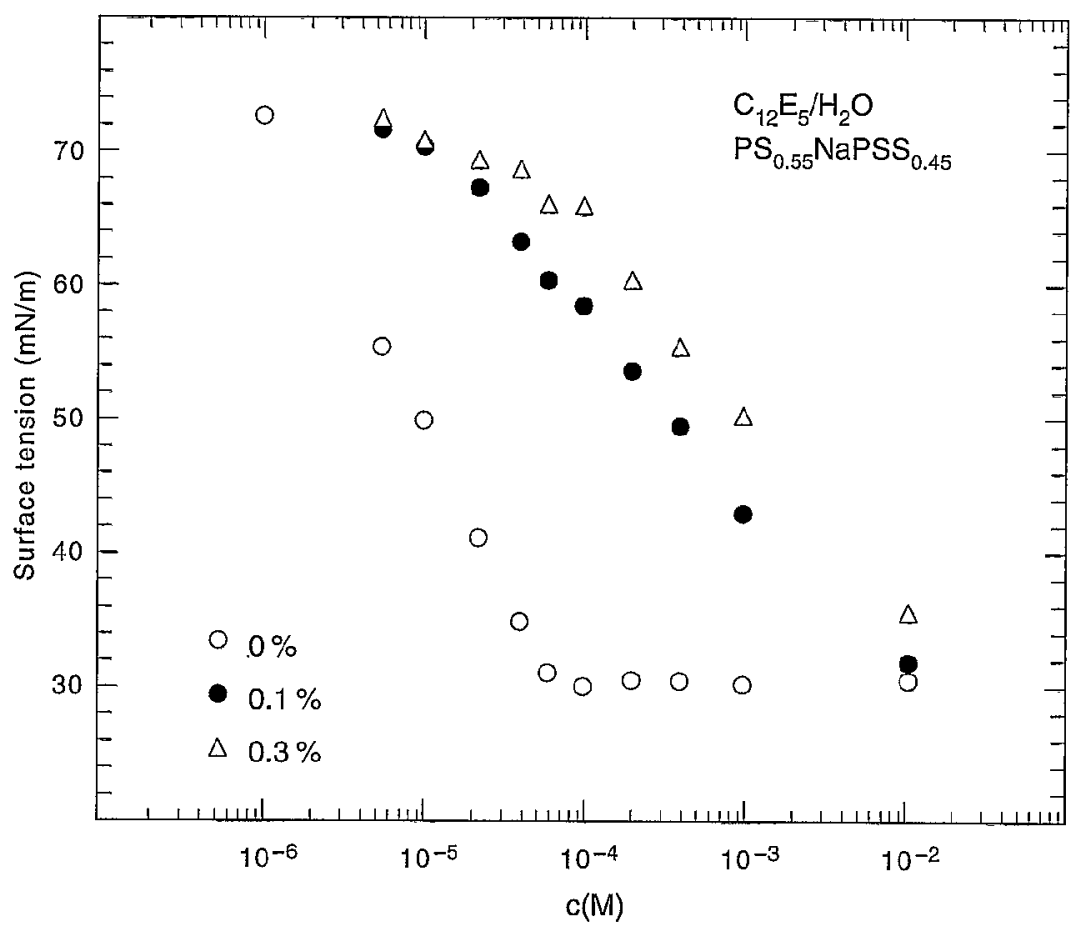

Figure 3

Surface tension of the $\mathrm{C}_{12} \mathrm{E}_{5}$ /water $/$ PSS $(x=0.45)$ system versus surfactant concentration. Experimental data for the binary $\mathrm{C}_{12} \mathrm{E}_{5} /$ water system are shown with empty circles, full circles correspond to $0.1 \mathrm{wt} \%$ of polymer and triangles to $0.3 \mathrm{wt} \%$ of polymer. After [7]. 
surface tension for pure $\mathrm{C}_{12} \mathrm{E}_{5}$ /water system and with addition of $0.1 \mathrm{wt} \%$ and $0.3 \mathrm{wt} \%$ of PSS $(x=45 \%)$. The surface tension curves suggest that the addition of polymer depletes the surface in surfactant molecules which bind to the polymer in the solution.

$\mathrm{C}_{12} \mathrm{E}_{5}$ in water self assembles into a rich variety of phases [16]. Our experimental data are concentrated in the region of high surfactant content (from $65 \mathrm{wt} \%$ to $85 \mathrm{wt} \%$ ) where a lamellar $\mathrm{L}_{\alpha}$ phase exists at room temperature. Several freeze fracture electron microscopy images, taken for various polymer concentrations at several degrees of sulfonation show a well defined lamellar structure and the interlayer distance is in very good agreement with SAXS-determined values [7]. The surfaces exposed by cleavage are mid-sections through the hydrophobic centre of the bilayer. These surfaces appear smooth for the binary $\mathrm{C}_{12} \mathrm{E}_{5} /$ water mixture. In contrast to that, for the ternary $\mathrm{C}_{12} \mathrm{E}_{5}$ /water /polymer systems there are additional objects clearly visible on the images (Fig. 4). Because of the cleavage properties of the freeze-fractured bilayers the objects seen cannot be attached to the hydrophilic surfaces of the lamellae but have to be enclosed inside the bilayers. The concentration of these objects scales with the concentration number of polymer molecules present in the samples and their size well corresponds to the size of polymer molecule. We concluded that the observed objects are PSS molecules confined inside the bilayers. Freeze fracture electron microscopy results unequivocally demonstrate that the polymer molecules enter bilayers and remain incorporated inside them for any charge content between 30 and 90 percent. There is a pronounced polymer-surfactant interaction (evidenced from surface tension data) that leads to the deformation of the lamellar structure (evidenced from SAXS data, see [7]. The polymer incorporation inside bilayers is the first observation of this kind in a surfactant/water/polymer system. Together with former studies on different systems, it illustrates the great variety of possible configurations of polymers chains in lamellar phases.

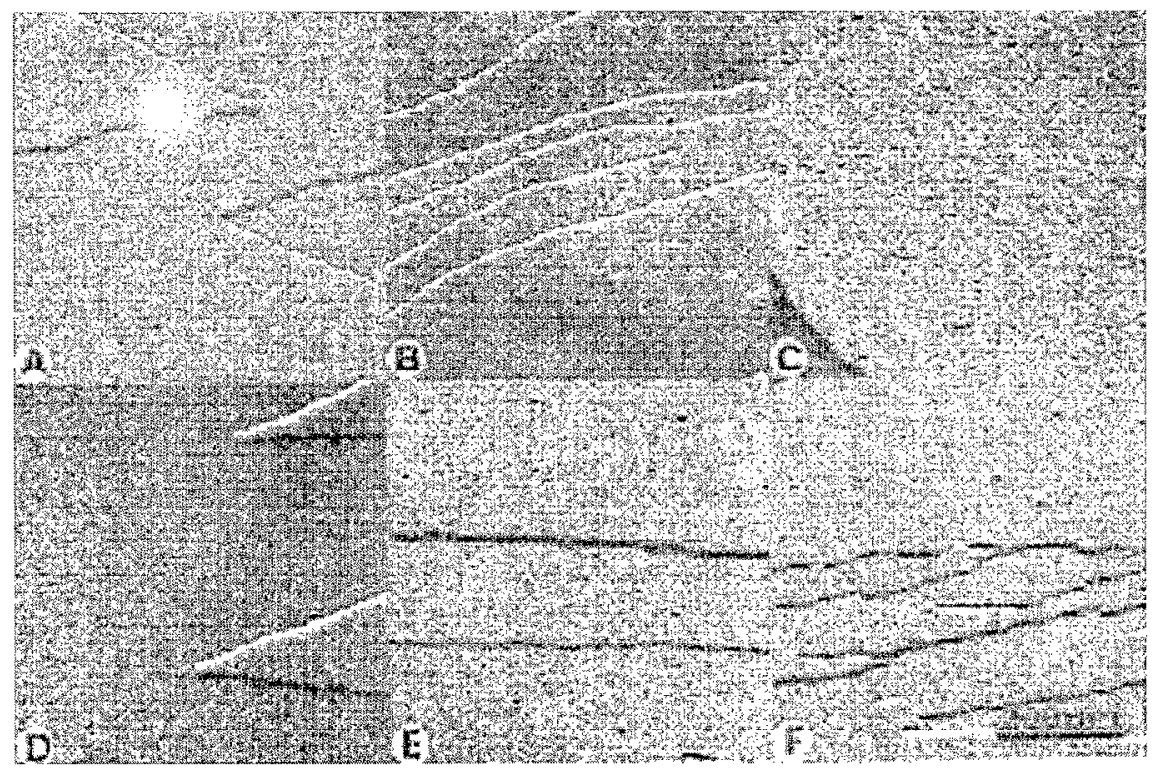

Figure 4

Freeze fracture electron microscopy images for samples with and without PPS

A: binary $\mathrm{C}_{12} \mathrm{E}_{5} /$ water system; $77.2 \mathrm{wt} \%$ surfactant.

$\mathrm{B}$ and C: sulfonation degree $x=0.3$, polymer concentration $0.2 \mathrm{wt} \%$ (B) and $2.3 \mathrm{wt} \%$.

$\mathrm{D}, \mathrm{E}, \mathrm{F}$ : sulfonation degree $x=0.9$, polymer concentration $0.2 \mathrm{wt} \%(\mathrm{D}), 0.9 \mathrm{wt} \%(\mathrm{E}), 2.2 \mathrm{wt} \%(\mathrm{~F})$. The surfactant to water ratio is the same in all the samples. After [7]. 


\section{POLYELECTROLYTE-SURFACTANT MIXED MONOLAYERS}

The polyelectrolyte studied is a statistical copolymer of acrylamide (AM) and acrylamido methyl propane sulfonate (AMPS) with a degree of charge $x=25 \%$. The polymer molecular weight is $\mathrm{M}_{w}=2.810^{6}$ $\left(\mathrm{M}_{w} / \mathrm{M}_{n}=1.5\right)$. Polymer solutions were ultrafiltrated and in such conditions, the polymer is not surface active for concentrations below $2000 \mathrm{ppm}$. We have measured the surface tension of the mixed solutions with $\mathrm{C}_{10} \mathrm{E}_{5}$, AOT and $\mathrm{C}_{12} \mathrm{TAB}$. At the difference of PSS, there is no surface tension modification in $\mathrm{C}_{10} \mathrm{E}_{5}$ solutions. This difference probably arise from the fact that the styrene monomers are much more hydrophobic than the acrylamide ones and are able to deplete the surface in surfactant molecule. However, the ionic surfactants of opposite charge have opposite effects: the surface tension is considerably lowered upon polymer addition (Fig. 5). Here, the polymer co-adsorb at the surface with the surfactant and forms a thin surface layer where the polymer is stretched out below the surface. More details on this work can be found in the paper by Asnacios et al in this issue, and on [17].

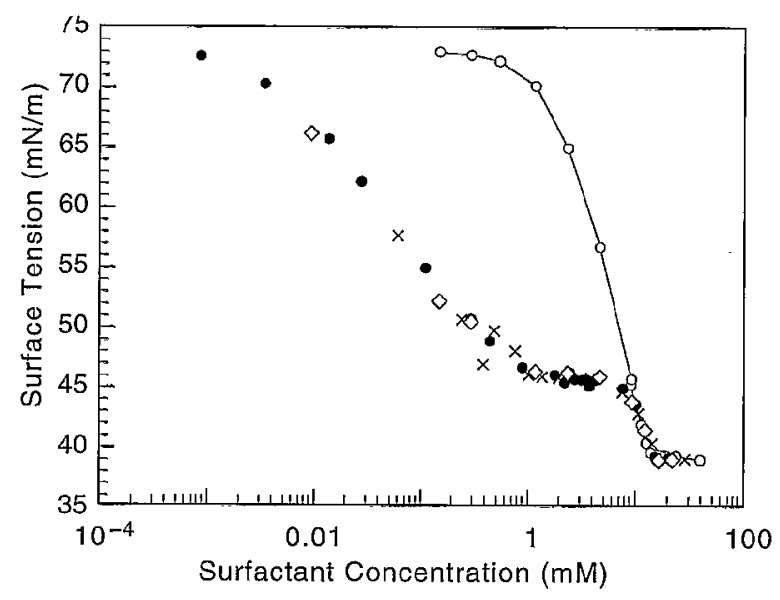

Figure 5

Surface tension of the DTAB/water/PAMPS versus surfactant concentration for different polymer concentrations: (open circles) without polymer;

(open triangles) $7 \mathrm{ppm}$;

(diamonds) $75 \mathrm{ppm}$;

(crosses) $350 \mathrm{ppm}$;

(filled circles)750 ppm. After [17].

\section{ACKNOWLEDGMENTS}

Most of these studies have been performed at the Laboratoire de physique de l'École normale supérieure in collaboration with E.K. Mann, J. Meunier, S. Henon, L.T. Lee and V. Bergeron for the PDMS work, E. Radlinska, W. Urbach, F. Lafuma, C. Williams, R. Ober, and T. Gulik for the PSS work, and A. Asnacios and J. F. Argillier for the AMPS work.

\section{REFERENCES}

1 Interactions of Surfactants with Polymers and Proteins (1993), edited by E. D. Goddard and K. P. Ananthapadmanabhan, CRC Press, Inc., Florida.

2 Lindman B. (1992), Adv. Colloid Interface Sci., 41, p. 149.

3 Ligoure C., G. Bouglet, and G. Porte (1993), Phys. Rev, Lett., 71, p. 3600.

4 Singh M., R. Ober, and M. Kleman (1993), J. Phys. Chem., 97, p. 11108.

5 Kekicheff P., B. Cabane, and M. Rawiso (1984), J. Colloid Interface Sci., 102, p. 51 .

6 Bagger-Jörgensen H., U. Olsson, and I. Iliopoulos (1994), J.Phys.Chem., 98, p. 1500.

7 Radlinska E.Z., T. Gulik, F. Lafuma, D. Langevin, W. Urbach, C. Williams and R. Ober (1995), Phys. Rev. Lett., 74, p. 4237.

8 Mann E.K, D. Langevin (1991), Langmuir, 7, p. 1112.

9 Mann E.K., S. Henon, D. Langevin and J. Meunier (1992), J.Physique II. Langmuir, 2, p. 1683.

10 Vilanove R., D. Poupinet and F. Rondelez (1988), Macromolecules, 18 , p. 2880. B. Duplantier and H. Saleur (1989), Phys. Rev. Lett., 62, p. 2624.

11 Bergeron V. and D. Langevin (1996), Macromolecules.

12 Lee L.T., E.K. Mann, D. Langevin (1993), Macromolecules, 26, p. 7046.

13 Brochard F., J.M. di Meglio, D. Quéré and P.G. de Gennes (1991), Langmuir; 7, p. 335.

14 Essafi W., F. Lafuma and C. Williams (1994), Am. Chem. Soc. ACS Symp. Se., 548, p. 278.

15 de Gennes P.G., P. Pincus, R.M. Velasco and F. Brochard (1976), J. Physique, 37, p. 1461.

16 Strey R., R. Schomäcker, D. Roux, F. Nallet, and U. Olsson (1990), J. Chem. Soc. Faraday Trans., 86, p. 2253.

17 Asnacios A., D. Langevin and J.F. Argillier (1996), Macromolécules, 29, p. 7412.

Final manuscript received in January 1997 